DECISION TOOLS

ANAIYSIS

Project Summary

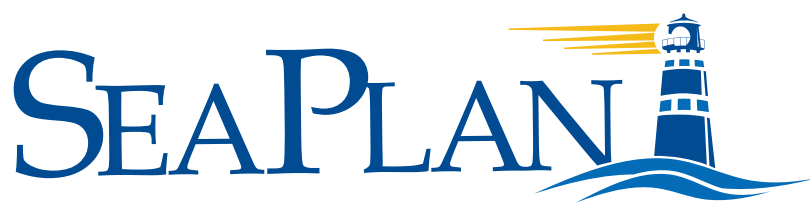

VIBRANT ECONOMIES • HEALTHY OCEANS

\title{
THE SCIENCE OF "WHAT IF":
}

\section{A PILOT STUDY IN NORTHERN}

\section{MASSACHUSETTS BAY USING}

\section{TWO ECOSYSTEM SERVICE}

TRADEOFF MODELS TO ASSESS

MANAGEMENT OPTIONS
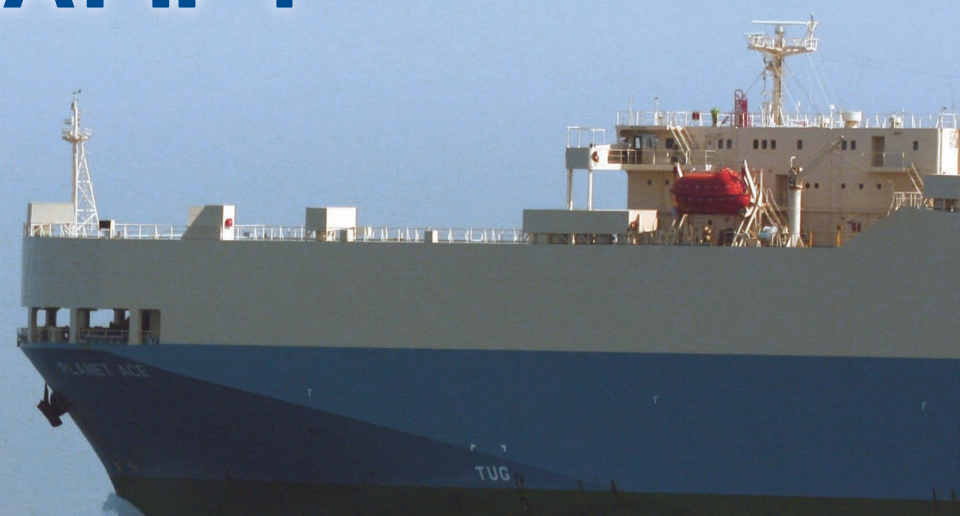

To demonstrate how ecosystem service tradeoff models might help decision makers predict the effects of proposed management approaches, SeaPlan collaborated with research teams from New England and the West Coast in 2009 to conduct a two and a half year pilot study analyzing multi-use issues in Northern Massachusetts Bay. The area includes active maritime commerce, two provisional wind energy areas and wellstudied, protected waters in the Stellwagen Bank National Marine Sanctuary. The two research teams applied different modeling approaches intended to support resource managers during decision making processes.

One team led by researchers from the National Center for Ecological Analysis and Synthesis (NCEAS) used the concept of efficiency frontiers from the field of economics to examine how siting an offshore wind farm would affect the ecological and economic aspects of commercial fishing and whale watching. The other team led by researchers from Boston University and University of Vermont used a complex platform called Multiscale Integrated Model of Ecosystem Services (MIMES) to simulate the interplay between commercial fishing, whale watching, offshore wind energy and conservation. To make the technical results understandable to a broad audience, researchers created a user-friendly interface called the Marine Integrated Decision Analysis System (MIDAS).

The Northern Massachusetts Bay pilot study demonstrated that ecosystem service tradeoff models can improve understanding of complex interactions within human-marine ecosystems and help visualize likely outcomes resulting from management actions taken across multiple sectors. The research suggests such tools can point to options that are more comprehensive and cost-effective when compared to typical sector-by-sector ocean management. 


\section{Finding Balance in a Shared Ocean}
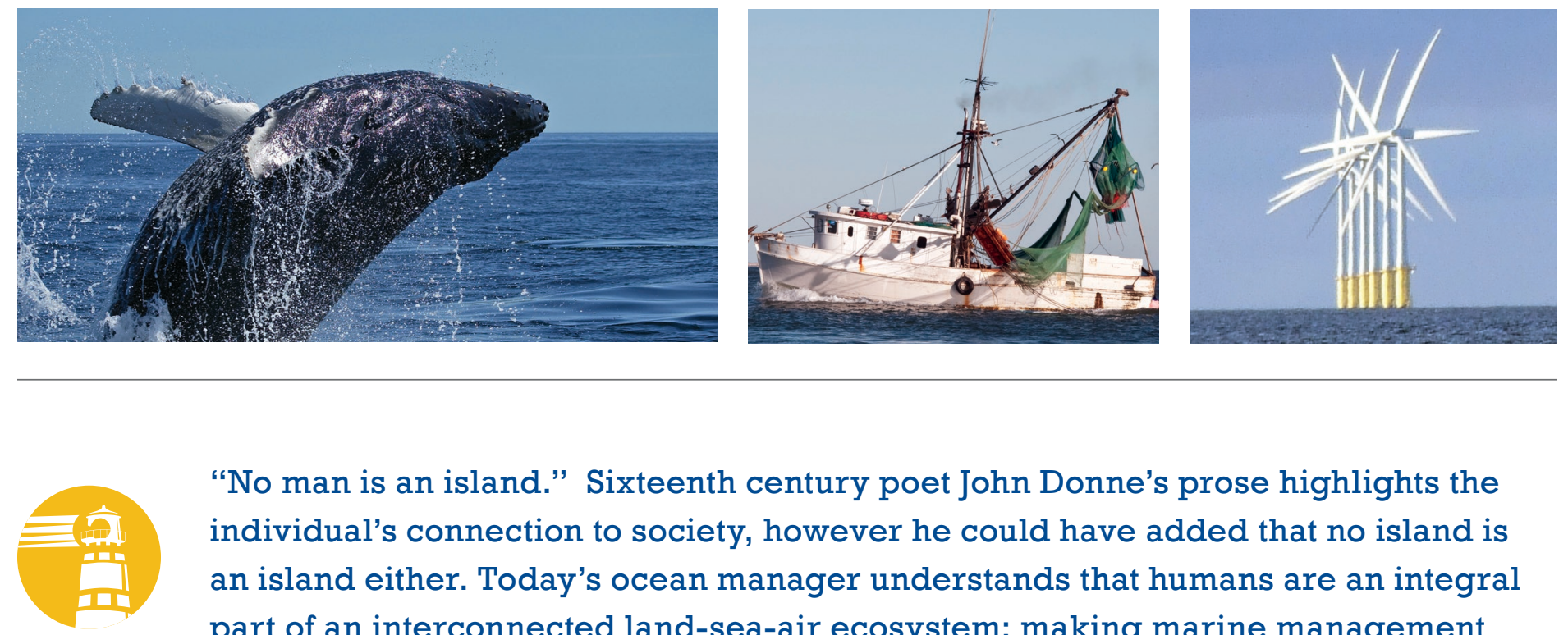

"No man is an island." Sixteenth century poet John Donne's prose highlights the individual's connection to society, however he could have added that no island is an island either. Today's ocean manager understands that humans are an integral part of an interconnected land-sea-air ecosystem; making marine management decisions complex and far reaching. New computing technologies can help people understand interactions among economic, social and ecological elements of the marine environment - providing critical analytical support to developing sound solutions to real world challenges.

One way to improve the decision making process is to characterize the ocean system and better understand how its components interact. Scientists have developed many computer models that run a suite of calculations and simulations to represent the complex relationships among natural and human systems. These models can project how the ocean will change in response to proposed management approaches; thus allowing decision makers to weigh the costs and benefits of each decision before it is made. Collectively called ecosystem service tradeoff models, these tools are useful to a wide range of people doing work in areas like maritime business planning, regional economic development, climate resiliency, marine conservation and national security.
Various groups have developed modern marine ecosystem service models, such as InVEST, ARIES, and MIMES. An emerging front for ecosystem service tradeoff analysis is the application of these tools to "real world" situations. This was the impetus for SeaPlan to spearhead a pilot study to apply and compare results of two tradeoff analysis approaches to resource management issues in Northern Massachusetts Bay. 
Study Area
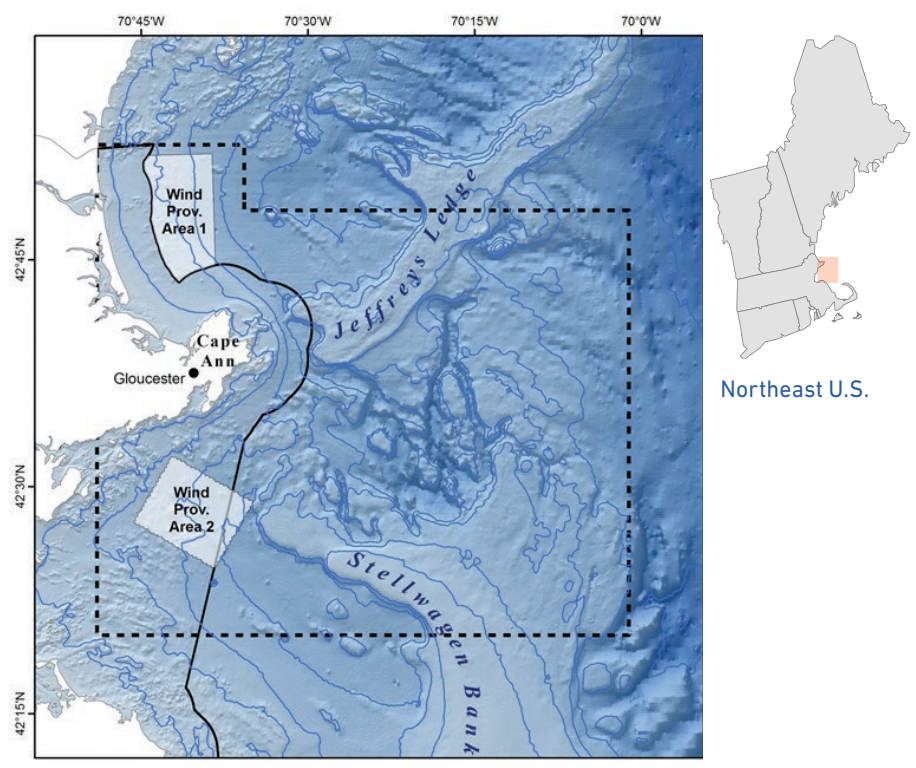

Northeast U.S.
SeaPlan chose to focus on Northern Massachusetts Bay and much of Stellwagen Bank for this pilot study because of its ecological, economic and cultural importance; and the rich data sets available on the area from academic and governmental researchers. A portion of the study area is also addressed by the Massachusetts Ocean Management Plan, which further enhanced the pilot project's utility for ocean managers -offering another tool that may help inform Plan implementation and updates.

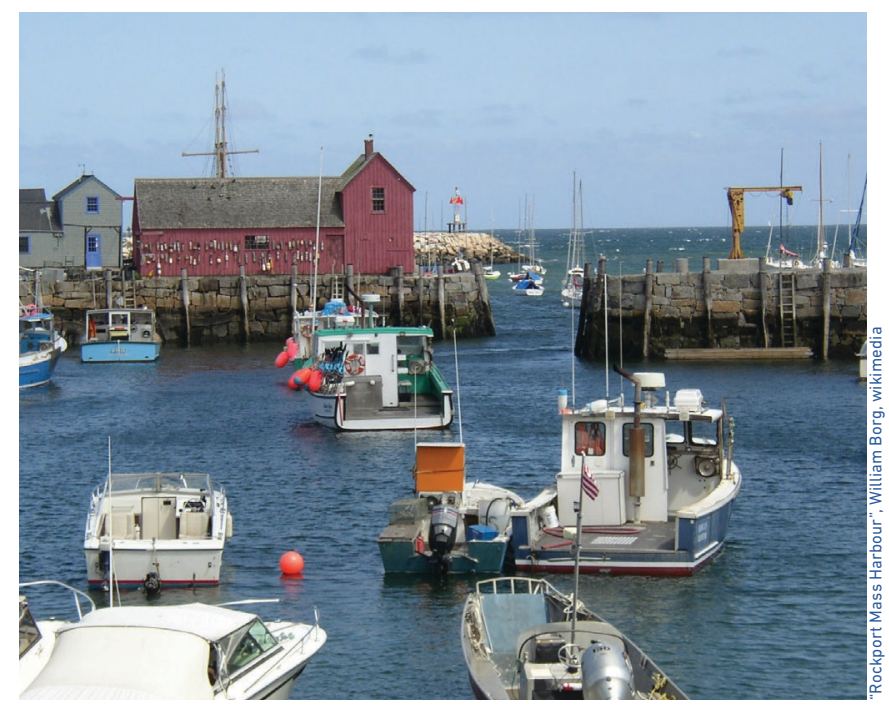

People benefit from many ocean resources and processes. Collectively, these benefits are called "ecosystem services" and include food production, climate regulation, energy production, nutrient cycling and recreation.

\section{Power of Partners}

The success of this study is the result of effective

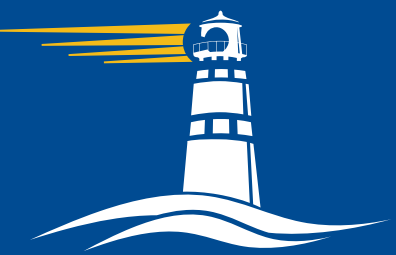
collaboration among SeaPlan,

the research teams and the project advisors whose collective expertise included marine ecology, resource economics, computer modeling, marine spatial planning, stakeholder engagement and geographic information systems.

\section{Pilot Study Manager \\ - Nicholas Napoli, SeaPlan}

\section{Efficiency Frontiers Team}

- Crow White, Ph.D.

Assistant Professor, Biological Sciences Department California Polytechnic State University

- Benjamin S. Halpern, Ph.D. and Carrie V. Kappel, Ph.D. National Center for Ecological Analysis and Synthesis, University of California, Santa Barbara

\section{MIMES Team}

- Les Kaufman, Ph.D. and Irit Altman, Ph.D. Boston University

- Roel Boumans, Ph.D. and Joe Roman, Ph.D. Gund Institute for Ecological Economics, University of Vermont

\section{MIDAS Team}

- Suchi Gopal, Ph.D., Josh Pitts, and Greg Meyer Boston University

\section{Pilot Study Data Providers \& Project Advisors}

- Christopher Clark, Cornell University

- Bob Boeri, Todd Callaghan, Emily Huntley, and Dan Sampson Massachusetts Office of Coastal Zone Management

- Marla Ranelletti and Shaun Walbridge

National Center for Ecological Analysis and Synthesis (NCEAS)

- Rachelle Jacobson and Amanda Johnson

National Oceanic and Atmospheric Administration

- Kerry Lagueux and Brooke Wikgren

New England Aquarium

- Leila Hatch, Stellwagen Bank National Marine Sanctuary

- Kim Selkoe, Andrew Rassweiller, and Christopher Costello University of California, Santa Barbara

- Lewis Incze, University of Southern Maine

This research was funded by the Gordon and Betty Moore Foundation. 


\section{Two Approaches}

This pilot study provided a rare opportunity to explore the utility of two ecosystem tradeoff models focused on the same resource area.

\section{Efficiency Frontiers}

Researchers from the National Center for Ecological Analysis and Synthesis (NCEAS) applied the economic concept of efficiency frontiers to the study area system and explored system response to various offshore wind energy development scenarios. Researchers used a coupled biological-economic model to estimate the spatial distribution and net present value of commercial fishing, whale watching and offshore wind energy in response to potential wind farm development in two provisional wind energy areas established in the Massachusetts Ocean Management Plan. The research team considered the full range of potential development within the provisional areas, with up to four wind turbines per square kilometer.

Researchers modeled two management approaches.

- Single-sector: All sectors pursued maximum value independently. Energy development focused on the most profitable areas, while fishery and whale-watching sectors adjusted.

- Multisector: Energy sector coordinated wind farm design with management of the other sectors to maximize value overall. This was deemed a better approach because it identified management solutions that could increase the economic and ecological value of each sector.

The Efficiency Frontier represents the preferable options. In this illustration, Option A results in lower benefit for both sectors than Option B and all other options that fall below the Efficiency Frontier.

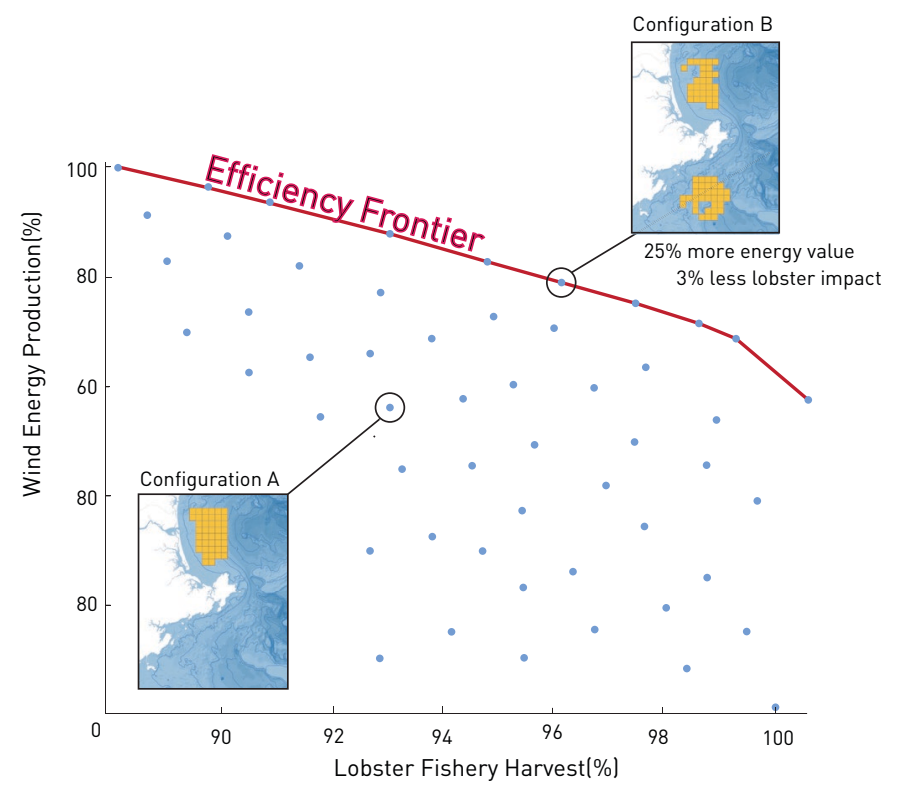

\section{MIMES/MIDAS}

Scientists from a number of East Coast institutions (Boston University, University of New Hampshire, New England Aquarium, University of Vermont, Stellwagen Bank National Marine Sanctuary) applied an approach called Multiscale Integrated Models of Ecosystem Services (MIMES) to develop a spatially and temporally explicit model of ecosystem function that includes interactions within and between natural and human components of the Northern Massachusetts Bay system. The approach strives to consider all relevant coastal and marine ecosystem and economic data, quantify the relationships between them, calculate ecosystem reaction when conditions are altered, and visually represent the consequences of those changes.

The MIMES model integrates numerous data sets and incorporates expert knowledge of functional relationships. The goal of MIMES is to understand how a suite of ecosystem services change over space and time as a result of human activities. For example, one set of MIMES scenarios explored how the construction of offshore wind turbines affects ecosystem services that support different fisheries and biodiversity. Another set of scenarios examined the consequences of increased fishing for common prey species like sand lance and herring. Researchers developed a visualization and decision support tool called the Marine Integrated Decision Analysis System (MIDAS), which is a graphic end-user interface to showcase MIMES outputs. The platform is an interactive, web-based environment using open source GIS capable of facilitating participatory mapping and social collaboration. In addition to aiding visualizations, MIDAS is designed to promote stakeholder engagement, encourage users to comment on model output and solicit input to help refine the model.

Together, the MIMES-MIDAS tool is designed to give managers a systematic way to characterize tradeoffs among industry sectors; evaluate the environmental and economic consequences of management alternatives; provide scientific grounding for management discussions; and examine proposed uses of the ocean.

MIMES model output for scenarios examining the effect of increased fishing for forage species. These species, which include northern sand lance and Atlantic herring, are an important source of food for other fish and whales in the system. When harvested by humans they also provide a marketbased service to the fishery economy. Below, the spatial model outputs represent the relative change in whale biomass resulting from two forage fish harvesting scenarios. The results are shown for three portions of the whale watching season.

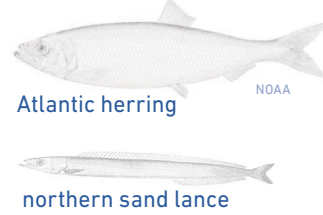

Change in distribution of humpback whales from baseline values

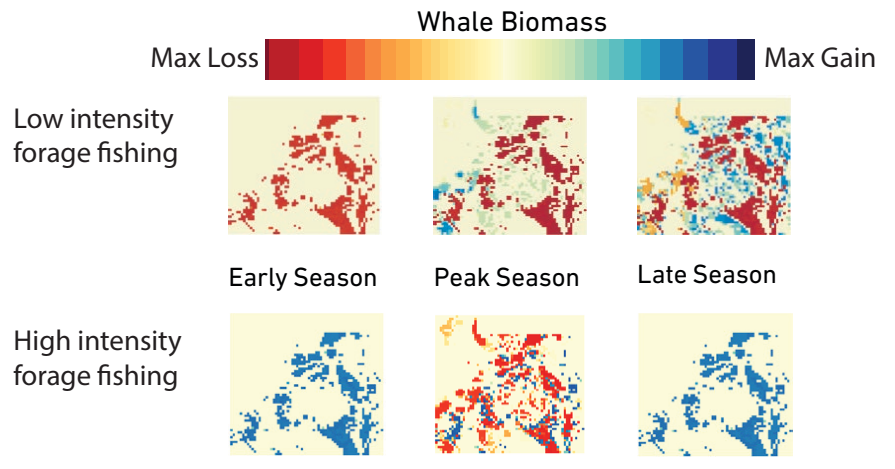



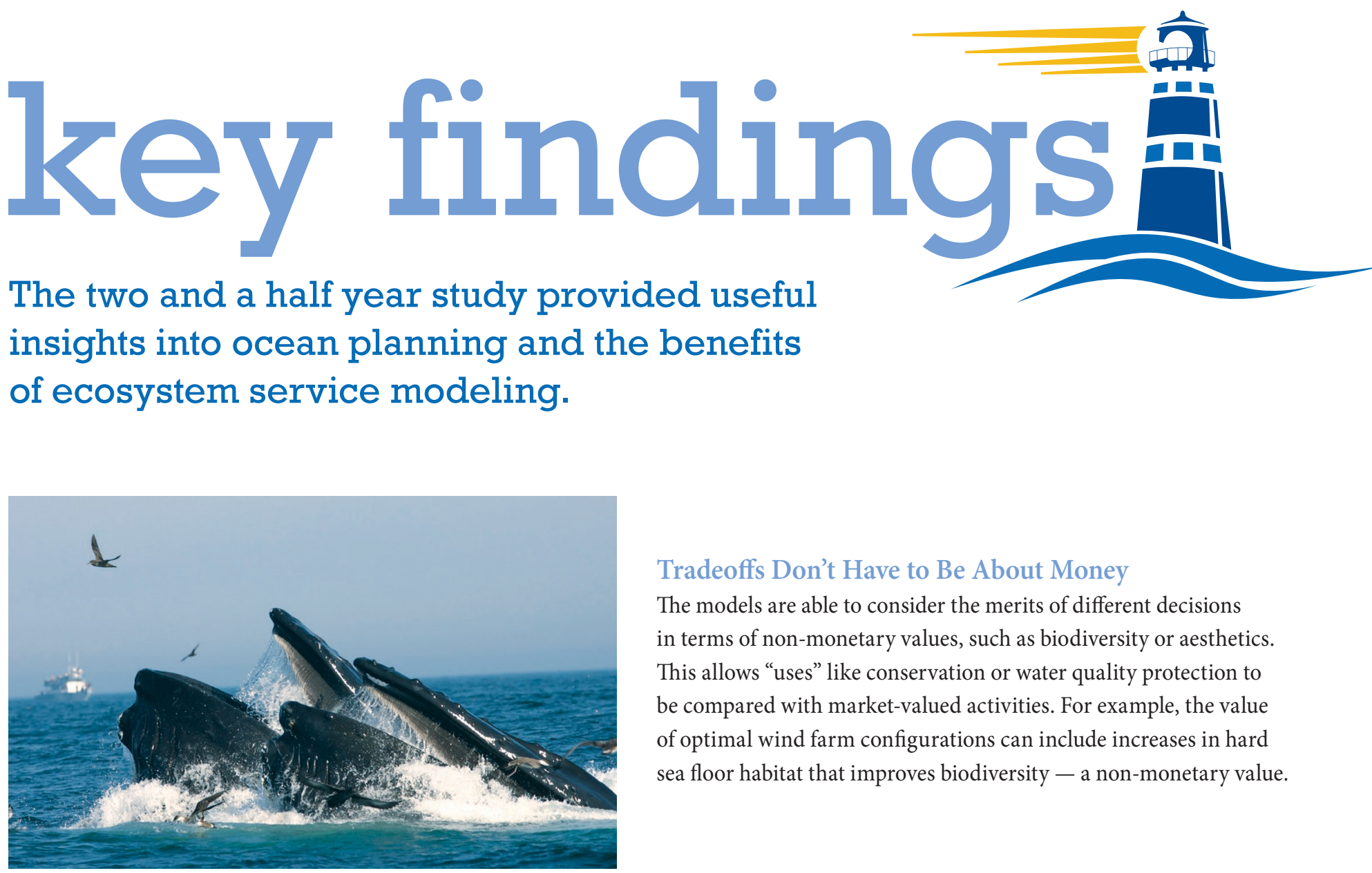

\section{Tradeoffs Don't Have to Be About Money}

The models are able to consider the merits of different decisions in terms of non-monetary values, such as biodiversity or aesthetics. This allows "uses" like conservation or water quality protection to be compared with market-valued activities. For example, the value of optimal wind farm configurations can include increases in hard sea floor habitat that improves biodiversity - a non-monetary value.

\section{Single-sector Management is More Costly than Multisector Management}

The work of the Efficiency Frontiers team demonstrated that using marine spatial planning (MSP) over conventional planning could prevent more than one million dollars in losses to the existing fishery and whale-watching sectors and could generate more than ten billion dollars in extra value to the energy sector. These values are conservative considering that the analysis focused on only a handful of sectors using a relatively small study area, and the framework demonstrated that the value of MSP increased as the number of sectors under consideration and study area increased.

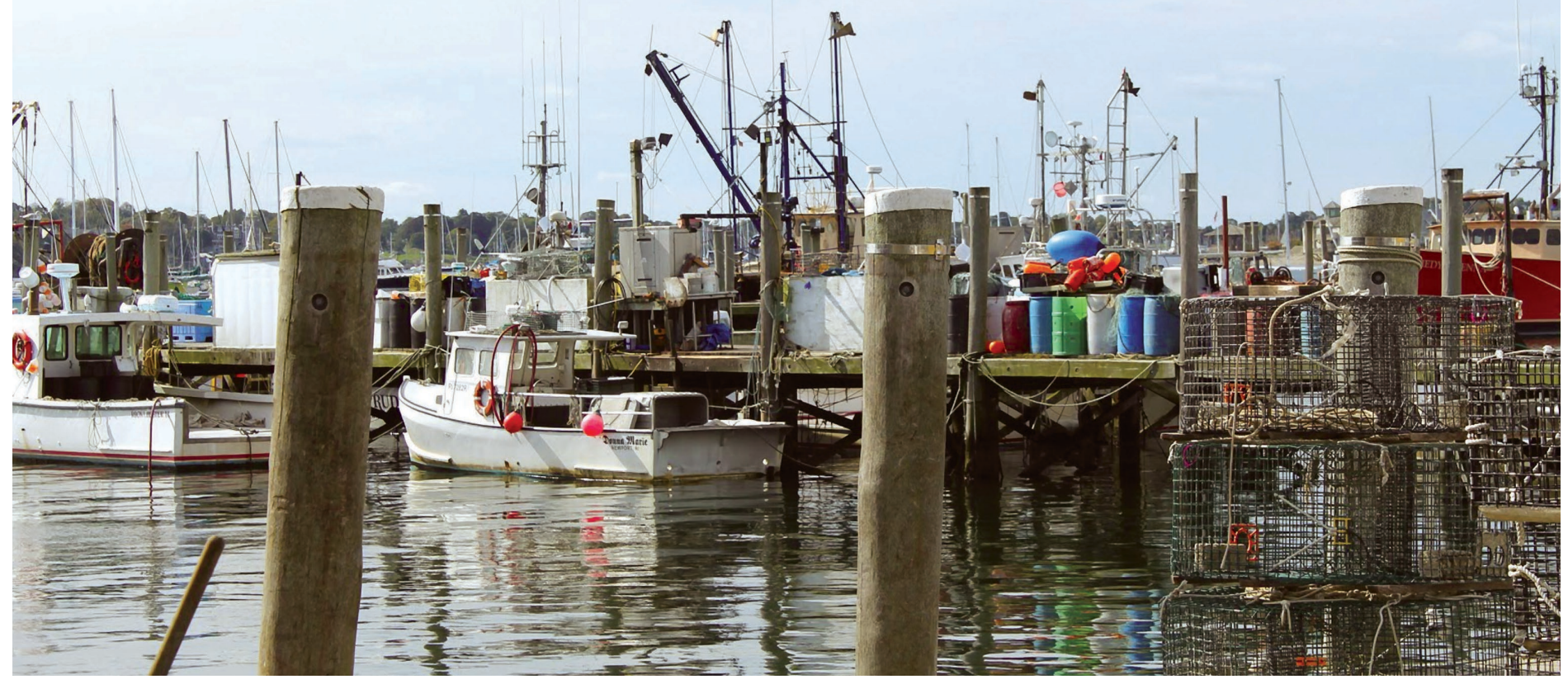


"The spatially explicit tradeoff analysis we conducted for Massachusetts Bay demonstrates the viability and value of strategic ecosystem-based MSP [Marine Spatial Planning] for informing and rationalizing the often entrenched debates around spatial allocation of marine resources, focusing them on objective conflicts and identifying efficient solutions for improving management outcomes."

- From White, Crow, Benjamin S. Halpern, and Carrie V. Kappel. "Ecosystem service tradeoff analysis reveals the value of marine spatial planning for multiple ocean uses." Proceedings of the National Academy of Sciences 109, no. 12 (2012): 4696-4701

Tradeoff Analysis Tools Can Reduce Sector Conflicts The approaches used by both the Efficiency Frontiers team and the MIMES/MIDAS team can improve transparency in decisionmaking, thus avoiding unnecessary conflicts. The models instead focus debate on finding the most efficient tradeoffs that maximize value for all sectors.

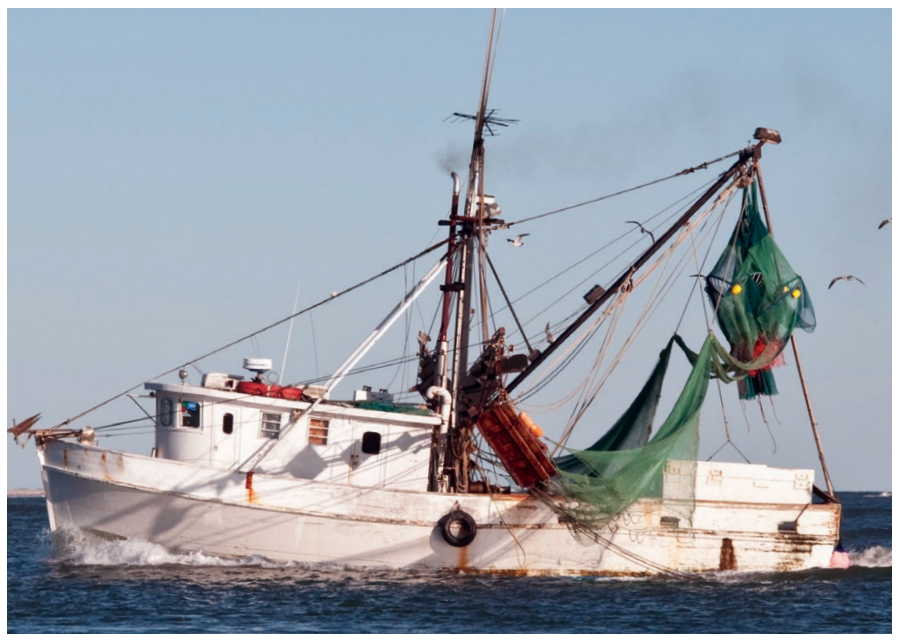

\section{Obscure Relationships Can Be Evaluated}

Given the complexity of interrelated natural and human systems, the consequences of decisions are not always apparent. Using the rigorous, science-based approach of tradeoff analysis can reveal unintended impacts and win-win opportunities that would not otherwise be apparent. For example, the anchoring structures of offshore wind farms provide hard seafloor habitat that improves a lobster fishery.

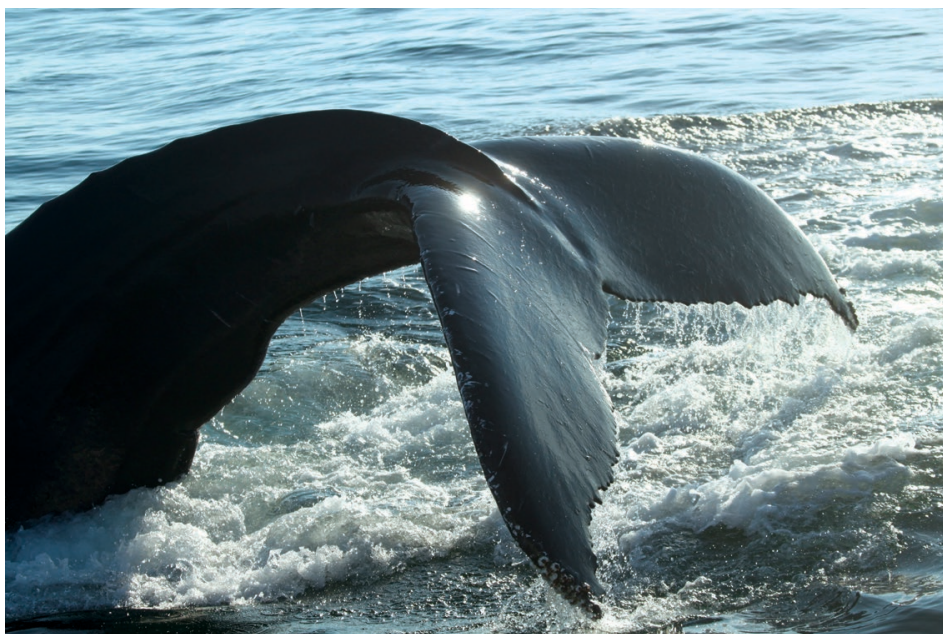

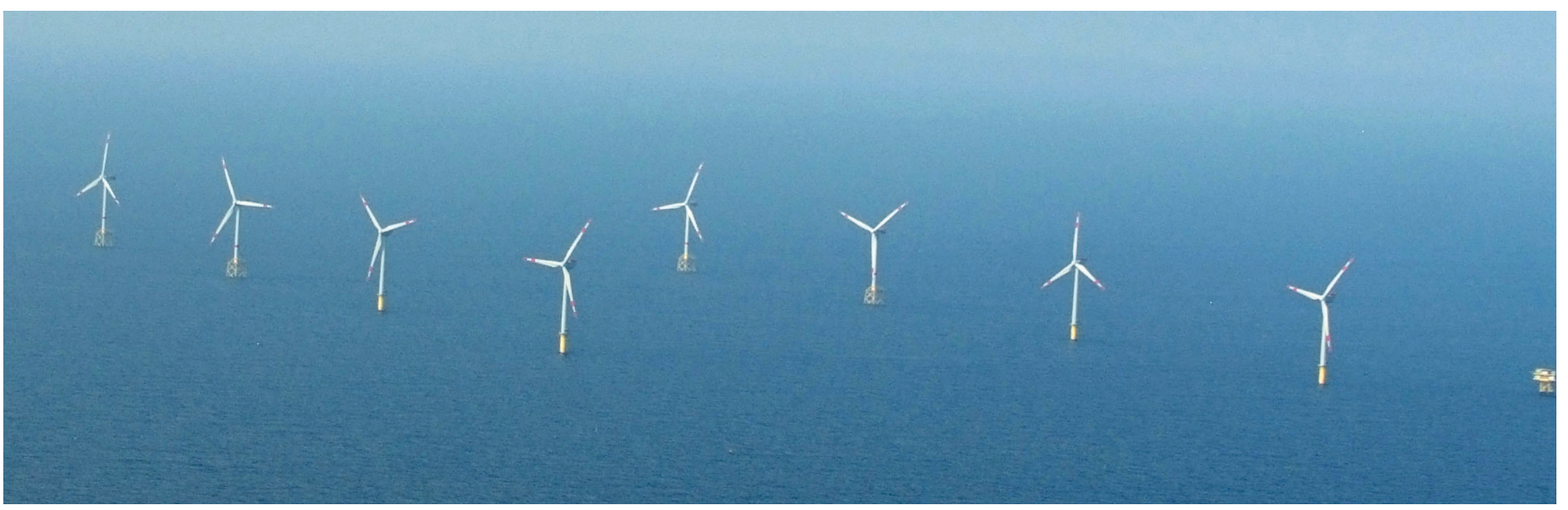


"The models are dynamic and spatially explicit, revealing ecosystem service tradeoffs and forecasting the outcomes of alternative policies.

Tools like these are essential for decision makers at various levels who are charged with managing complex systems in a sustainable fashion."

- Dr. Les Kaufman, Boston University Marine Program

Models Provide Useful Ways to Visualize Tradeoffs

Describing complex and dynamic ecosystems to stakeholders is a challenge. The pilot study produced animated maps that showed changes in animal distribution, economic production and biodiversity through time. Examining changes in ecosystem components simultaneously demonstrates the nature and intensity of tradeoffs and enables stakeholders to readily compare tradeoffs across a set of alternative management decisions.

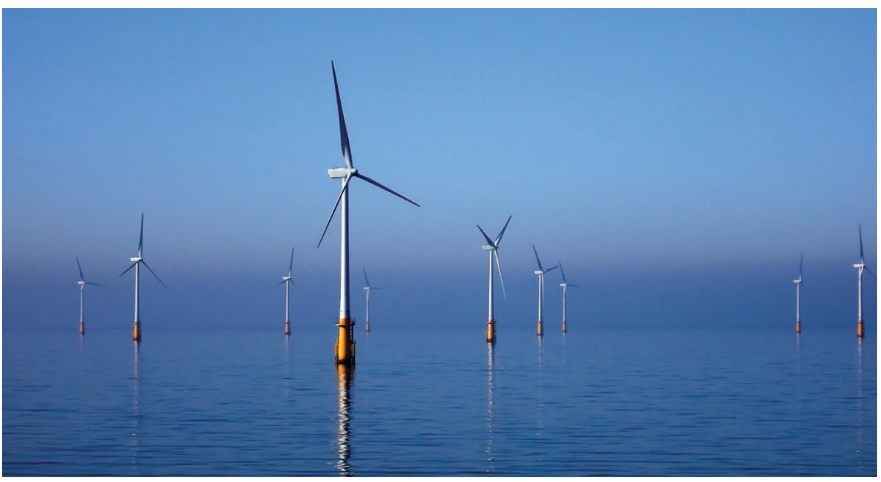

Models Can Reveal Cumulative Impacts

MIMES accounts for a variety of impacts specified for 13 modeled human activities, both singly and in aggregate. By assessing all impacts, the tool can dynamically forecast whether further interactions are likely to result from areas experiencing multiple impacts. Understanding and accounting for cumulative impacts and indirect effects is recognized as a key component of ecosystem-based ocean management.

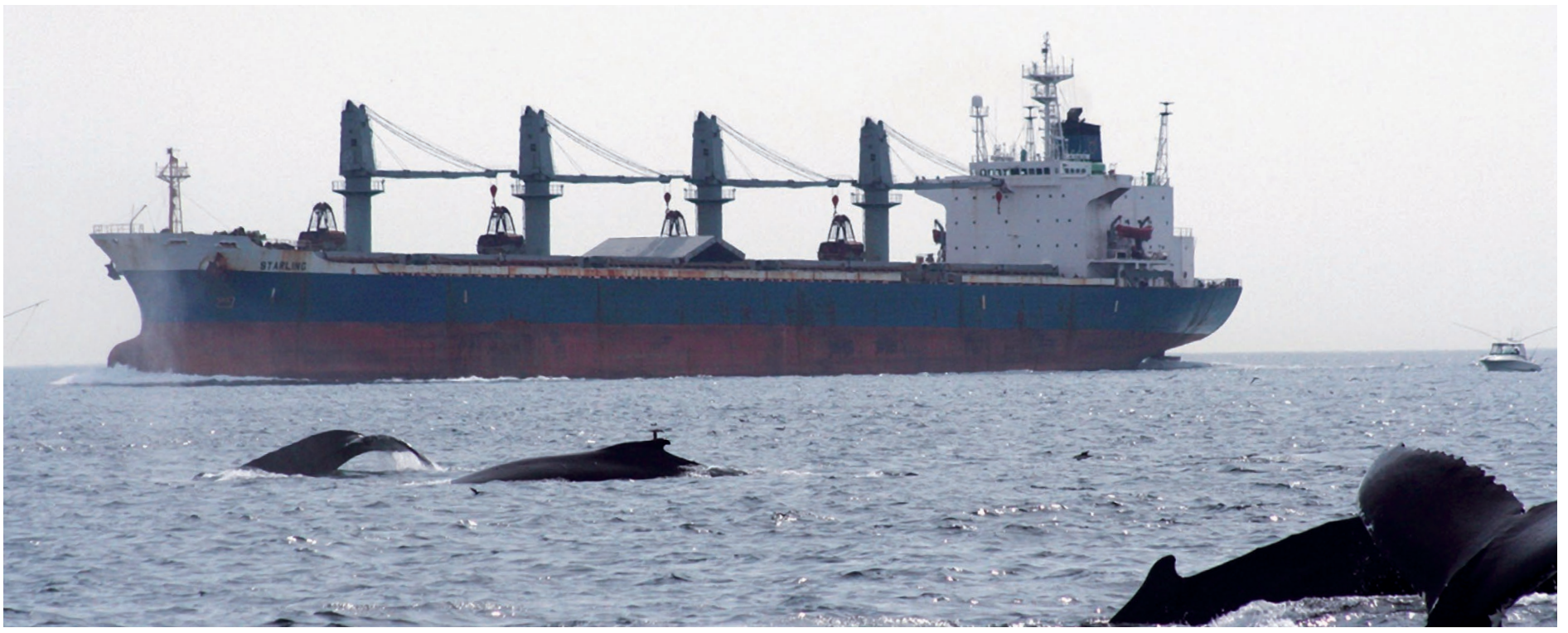




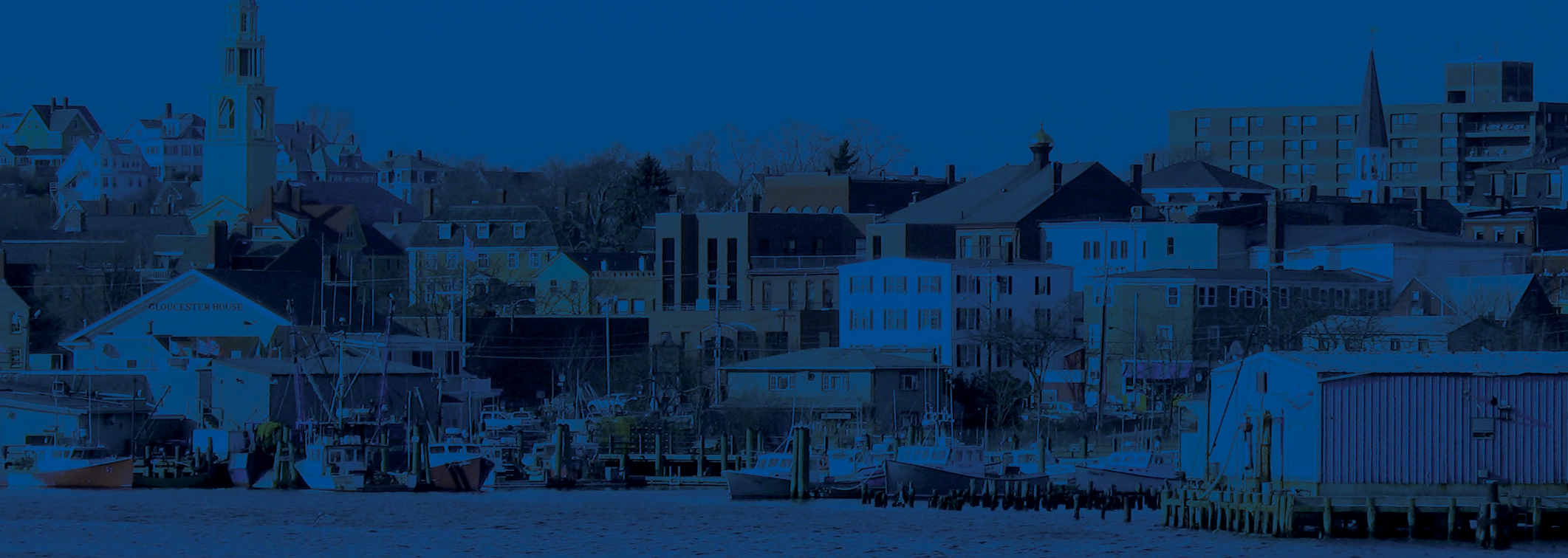

\section{Broad-based Value of Decision Tools}

Ecosystem service tradeoff models are useful to a wide-range of people. Ocean managers can use this kind of analysis tool to guide management and permitting decisions while minimizing conflicts. Ocean-dependent industries benefit from modeling when projecting costs, communicating impacts and securing permits. Communities with working waterfronts can use modeling to improve land and ocean planning that optimizes natural resource utility while protecting critical resources.

\section{SEAPLAN} VIBRANT ECONOMIES • HEALTHY OCEANS 